\title{
Teachers' feelings of safeness in school-family-community partnerships: Motivations for sustainable development in moral education
}

\author{
Nguyen Thi Ngoc Lien', Nguyen Thi To Khuyen², Nguyen Thi Tho ${ }^{3}$, Nguyen Ngan Hoa ${ }^{4}$, Nguyen Thi \\ Hanh $^{5}$, Chu Cam Tho ${ }^{6}$, Tuong Duy Hai ${ }^{7}$, Nguyen Van Bien ${ }^{8}$ \\ ${ }^{1,3,6,7,8}$ Hanoi National University of Education, Hanoi, Vietnam \\ ${ }^{2}$ National Taiwan Normal University, Taipei, Taiwan \\ ${ }^{4}$ Victoria Thang Long School, Hanoi, Vietnam \\ ${ }^{5}$ Diplomatic Academy of Vietnam, Hanoi, Vietnam \\ ${ }^{6}$ The Vietnam National Institute of Educational Sciences, Hanoi, Vietnam
}

\begin{abstract}
Article Info
Article history:

Received Jun 12, 2020

Revised Dec 23, 2020

Accepted Jan 23, 2021

\section{Keywords:}

Effective moral education

Motivation

Partnerships

Sustainable moral education

Teachers' safeness

ABSTRACT

This study aims to get insights into teachers' safety feelings in families, schools, and communities' partnerships to facilitate the Vietnam context's moral education process. We used a survey method with the instrument having 19 Likert-scale items, namely teachers' feelings of safeness in SFC partnerships (SSFC). The data from 371 Vietnamese teachers followed a simple random sampling strategy. We conduct multiple regression analyses to get insight into the relationship between four groups of variables and teachers' feelings of safeness, namely teachers' background, collaborated actions between teachers and families, families' mental encouragement for teachers, and collaborated actions between families and communities. These results find that the school level, collaborated actions between teachers and families, and families' mental encouragement for teachers are statistically significant to teachers' feelings of safety. Moreover, the variable group of collaborated actions between teachers and families records the highest positive beta value in multiple regression analyses. In other words, the improvement of collaborated actions between teachers and families is a critical motivation to leverage teachers' feelings of safeness in SFC partnerships. These results provide valuable information for sustainable development in moral education.
\end{abstract}

This is an open access article under the CC BY-SA license.

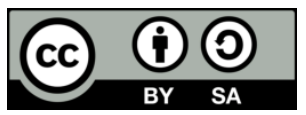

\section{Corresponding Author:}

Nguyen Van Bien

Hanoi National University of Education

165 Xuan Thuy Street, Cau Giay District, Hanoi, 10000, Vietnam

Email: biennv@hnue.edu.vn

\section{INTRODUCTION}

Moral education plays an essential role in modern complex society because of the influences on the development of students' personal worldviews. Van der Kooij, et al. [1] explained that every approach to moral education encompassed the underlying ontological beliefs: the purpose of human beings, how people should act, and people's roles in the world. Van der Kooij, et al. [1] emphasized that the influence of moral education on personal worldviews is inevitable and minimal. By enhancing the moral development of students, the quality of society was contributed. In other words, the importance of moral education emerged from a society perspective [2-4]. Facilitating students to understand the social world is the main domain to 
approach moral education [5]. Therefore, the investigations of moral education from the local context is a necessity to address social features. For example, while Peru was advocated as a diverse country with many indigenous people, moral education needs to be intercultural moral education to reach sustainable peace, ecological harmony, and socio justice [2]. Vietnam is another example since moral education was formed and defined based on Confucianism, policies, or major religions [6].

Families, schools, and communities inevitably affect moral education in Vietnam. Vietnam's moral education exists in two different systems, namely traditional morality and socialist morality [6, 7]. Informal channels in education are utilized for traditional morality, such as family educations and religious institutions. Meanwhile, socialist morality is implemented through formal channels of the national curriculum and in various social activities and movements [6]. Consequently, students are taught morality in families, schools, and communities as well. The collaborations of families, schools, and communities are valuable to impact students' outcomes [8-10]. In other words, none of the families, schools, and communities solely impacts moral education in Vietnam. The coordination among schools, families, and communities (SFC) become a prerequisite to facilitate moral education [11].

Teachers are crucial for the success of SFC partnerships. Schools might bring all three spheres of influence closer together by conducting high-quality communications and interactions at both the institutional and the individual levels [11]. At the institutional level, schools organize events and invite all families or send the same notifications to all families. The dialogues between parents and teachers at the meetings or talk by phone are examples at the individual level. At the institutional level, teachers are implicitly on behalf of schools to interact directly with parents. Besides, teachers also transmit students' and families' feedback to schools. Teachers directly implement moral education through at the individual level formal channels such as the national curriculum and are moral exemplars for students [12]

Psychology safety facilitates the effectiveness of learning in an educational environment [13-16]. The psychology safety in an educational environment enables members not to be punished even for negative consequences and they are comfortable in such environments [16]. Teachers often think about other people's reactions when making a decision. Teachers will probably abandon the acts that make others could criticize teachers. Psychology safety helps teachers overcome anxiety to implement innovative teaching practices $[16,17]$.

Research literature describes that teachers need to feel adequately safe to communicate confidently and cooperate effectively with families, schools, and communities. Swick (as cited in [18]) noted that feeling comfortable and secure was essential to have authentic, meaningful, and growth-promoting communications to empowering partnerships. However, in reality, many teachers do not feel adequate safeness. The following reasons can be explained these. First, while the model of SFC partnerships is student-centered [11], there were still differences in goals and agendas in families, schools, and community partnerships [19]. Consequently, families, schools, and communities have different emotions and actions. Second, teachers were not often faith enough in teachers' self-worth that lead teachers to be straggle to have positive relationships with families ([20]; as cited in [19]). Third, based on teachers' interviews qualitative analysis, the researcher [21] realized that teachers concerned about parents' insufficient attitude to conduct highquality dialogues.

Both internal and external factors influence the teachers' feeling of safeness in SFC partnerships [15] Notably, behaviors are bi-direction with environmental influences and personal factors, including attitude and particular features [22]. There are two main kinds of elements: 1) teachers' background characteristics; and 2) actions in SFC partnerships. While teachers are vital people to coordinate families, schools, and community partnerships, the insights of teachers' feeling of safeness are becoming prerequisites. Figure 1 illustrates the factors affecting teachers' feelings of safeness in schools, families, and community (SFC) partnerships. Geography school locations, teaching experiences, educational backgrounds, and school-levels are teachers' background characteristics. Collaborated actions between teachers and families, families' mental encouragement for teachers, and collaborated actions between families and communities are examined as actions in SFC partnerships. While many teachers do not feel adequate safeness, there is a need to explore factors related to teachers' feelings of safeness. While many studies concluded that psychology safety significantly correlated with teachers' voices $[13,15,16]$, a few studies investigated factors that could affect teachers' feelings of safeness. The researcher [16] confirmed ethical leadership would be positively related to psychological safety. However, how the actions in SFC partnerships affect teachers' feelings of safeness has not been revealed. The current study aims to reveal the factors affecting teachers' feelings of safeness in SFC partnerships, including personal and external factors. 


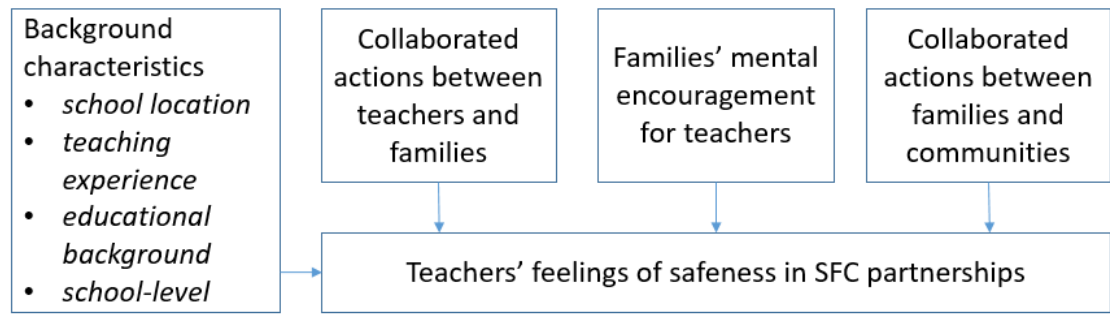

Figure 1. Theoretical framework for teachers' feelings of safeness in SFC partnerships

\section{RESEARCH METHOD}

\subsection{Research design}

We employed the survey research methodology to measure teachers' safeness in SFC partnerships in moral education. The cross-sectional survey was utilized to analyze relations between variables and the differences between sub-samples [23]. We surveyed in April and May 2019 in seven areas from the North to South Vietnam, including urban areas, rural areas, and highlands. We directly surveyed teachers at teachers' schools. All collected responses were analyzed using a quantitative method to address research questions.

\subsection{Sample}

In total, 371 in-service teachers responded to the questionnaire following a simple random sampling strategy. The majority of participants are female (77.4\%). We surveyed teachers in schools in 7 cities and towns in Vietnam. Most teachers are in primary schools, junior high schools, and senior high schools. 13.2\% of teachers are in continuing education where students have finished in junior high school and study in a range of different subjects. Teachers in other descriptive variables were illustrated in Table 1.

Table 1. The distribution of teachers by geographic area, teaching experience, and school level

\begin{tabular}{ccc}
\hline Variable & $\mathrm{n}$ & Percentage (\%) \\
\hline Geographic area & & \\
Urban & 205 & 55.3 \\
Rural & 129 & 34.8 \\
Highland & 37 & 10.0 \\
Teaching Experience & & \\
$\leq 10$ years & 116 & 31.3 \\
11-20 years & 154 & 41.5 \\
>20 years & 101 & 27.2 \\
Educational background & & \\
The degree of associate & 31 & 8.4 \\
Bachelor degree & 277 & 74.7 \\
Post-graduate degree & 63 & 17.0 \\
School-level & & \\
Primary school & 89 & 24.0 \\
Junior high school & 132 & 35.6 \\
Senior high school & 101 & 27.2 \\
Continuing education & 49 & 13.2 \\
\hline
\end{tabular}

\subsection{Development and validity of four sub-instruments to interpret teachers' feelings of safeness}

We developed the instrument, including four sub-instruments, to measure teachers' feelings of safeness and SFC partnerships. In total, the instrument has 19 5-point Likert-scale items (1=strongly disagree, and 5=strongly agree). There are four sub-questionnaires. The first sub-instrument is teachers' feelings of safeness; for example, "I feel comfortable when discussing with parents about students' moral educating." The second sub-instrument is about collaborated actions between teachers and families; for example, "Parents have done as committed in the coordination with teachers and schools." The third subinstrument is about families' mental encouragement for teachers, for example, "Parents expressed their gratitude to the teachers' efforts in educating their children." The fourth sub-instrument is about collaborated actions between families and communities, for example, "The local social organizations complimented family for well educate a child." Four sub-instruments aforementioned had six items, five items, five items, and three items, respectively. 
We conducted a factor analysis to examine whether items in each sub-instrument had something in common. We utilized the Kaiser-Mayer-Olkin (KMO) and Barlett's Test of Sphericity to verify sampling adequacy. All sub-instruments had the KMO greater than .6, indicating highly factorable [24]. Likewise, Barlett's Tests of Sphericity of four sub-instruments are statistically significant at $\mathrm{p}<.001$ level. The results indicate that the variables are correlated. For each sub-instrument, we found only one component by using the principal component and Varimax with Kaiser Normalization Rotation method. Table 2 illustrated the total variance that was accounted for explained by one factor identified in each sub-instrument. Besides, the result of KMO was in Table 2.

Table 2. The KMO and total variance of sub-instrument

\begin{tabular}{llcc}
\hline & \multicolumn{1}{c}{ Sub-instrument } & KMO & Total variance (\%) \\
\hline Sub-instrument 1 & Teachers' feelings of safeness & .794 & 41.18 \\
Sub-instrument 2 & Collaborated actions between teachers and families & .783 & 52.52 \\
Sub-instrument 3 & Families' mental encouragement for teachers & .813 & 56.47 \\
Sub-instrument 4 & Collaborated actions between families and communities & .664 & 72.15 \\
\hline
\end{tabular}

We utilize the Cronbach alpha to evaluate reliability as internal consistency. The calculated alphas of four sub-instruments were respectively .702, .772, .799 and .803. Researchers [24] indicated alphas' magnitude, with values between 0.70 to 0.90 considered reliable and reliable. The calculated alphas indicted reliable scales. The validation test results indicated that the questionnaire, including four sub-instruments, was reliable and valid to investigate teachers' feelings of safeness in SFC partnerships in moral education.

In the last part of the instrument, teachers were asked to respond to demographic information, including geographic area, teaching experience, and school level. An overview of all measured variables is given in Figure 1.

\subsection{Data analysis}

The first research question was explored by comparing the differences between subsamples. Using One-way ANOVA, the differences in teachers' feelings of safeness in different groups categorized by geographic area, teaching experience, and school-level were analyzed. The eta-squared was calculated to examine the effect size of differences between groups. Cohen [25] classified .01; .06; and 14, that is a small effect, a medium effect, and a large effect, respectively. All of the analyses were completed using SPSS 20.

The second research question was addressed in two steps. First, the correlation coefficients between all predictor variables and teachers' feelings of safeness were calculated. Then, the direct multiple regressions were utilized to examine the predictor variables that are most suitable to explain the variance of teachers' feelings of safeness in SFC partnerships in moral education. We constructed three different models for direct regression analyses: 1) Only predictor variables referring to teachers' personal background; 2) Only predictor variables referring to SFC partnerships; and 3) Full model.

\section{RESULTS AND DISCUSSION}

\subsection{Teachers' feelings of safeness in SFC partnerships in moral education}

The mean of each domain was calculated to interpret overall teachers' feelings of safeness $(\mathrm{M}=4.26$, $\mathrm{SD}=0.437)$; opinion of collaborated actions between teachers and families $(\mathrm{M}=3.95, \mathrm{SD}=0.518)$, opinion of families' mental encouragement for teachers $(\mathrm{M}=4.10, \mathrm{SD}=0.495)$, and opinion of collaborated actions between families and communities $(\mathrm{M}=3.70, \mathrm{SD}=0.748)$. The boxplots below illustrate the distributions of each domain as shown in Figure 2. The quartile 1 (Q1) of teachers' feelings of safeness is about 4.25. In other words, Vietnamese teachers felt safe in SFC partnerships. Similarly, the Q1s of two domains, which are the opinion of collaborated actions between teachers and families and the opinion of families' mental encouragement for teachers, is around 4.00. For opinion about collaborated actions between families and communities, while the Q1 is the lowest, the interquartile range (IQR) is the biggest. One can say that Vietnamese teachers had a diversity of opinions about collaborated actions between families and communities. 


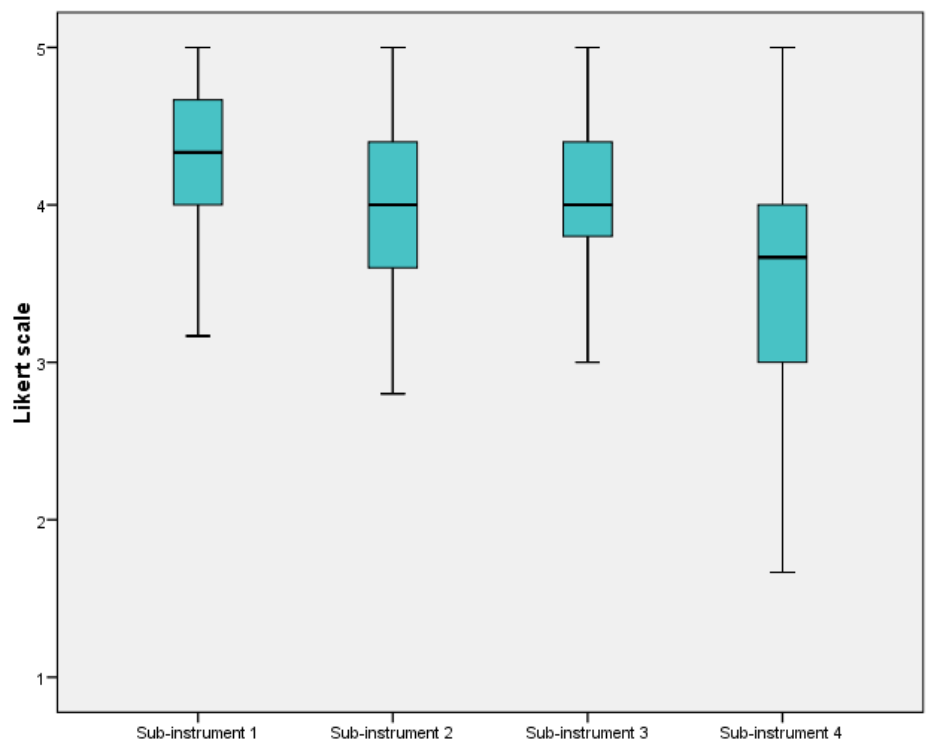

Figure 2. Distribution of each sub-instrument

\subsubsection{Differences in teachers' feelings of safeness based on background characteristics}

We utilized one-way ANOVAs and the post-hoc comparisons to examine whether there is any difference from subsamples' feelings of safeness in SFC partnerships. Table 3 illustrates the mean (M) and standard deviation (SD) of each group. The post hoc comparisons are shown in Table 4. Urban teachers feel the safest in SFC partnerships. While urban teachers feel safest comparing to rural or highland teachers, standard deviations (SDs) of urban teachers are the smallest. Urban teachers are less diverse than both rural and highland teachers in terms of feeling safe in SFC partnerships. The one-way between-groups ANOVA was conducted to explore differences in teachers' feelings of safety in SFC partnerships based on demographic categories. There were no statistically significant differences at the $p<.05$ level among geographic groups.

In contrast, there were statistically significant differences at the $p<.05$ level among teaching experience groups $(F(2,368)=6.9, p=.001)$; educational background groups $(F(2,368)=5.5, p=.004)$ and at the $p<.001$ level among school-level groups $(F(3,367)=10.0)$. Experienced teachers feel safer than least experienced teachers in SFC partnerships. The lower the educational background teachers have, the fewer safeness teachers feel. Primary teachers feel the safest in SFC partnerships. Overall, teachers who have more than 20 teaching years or degrees of associate or teach in primary schools feel safest in SFC partnerships. Based on the eta squared, actual differences in mean scores between groups were small among teaching experience groups $\left(\eta^{2}=.04\right)$ and educational background groups $\left(\eta^{2}=.03\right)$. Meanwhile, actual differences in mean scores between groups were medium among school-level groups $\left(\eta^{2}=.08\right)$.

Post hoc comparisons using the Tukey HSD test indicated that there was statistical significance among the mean scores among teaching experience groups, educational background groups, and school-level groups. For teaching experiences groups, the mean scores of teachers having more than 20 experienced years $(\mathrm{M}=4.39, \mathrm{SD}=0.403)$ are statistically significantly higher than either teacher having 11-20 teaching years $(M=4.24, S D=0.441)$ or least experienced teachers $(M=4.18, S D=0.437)$. For educational background groups, teachers holding degrees of associate $(\mathrm{M}=4.51, \mathrm{SD}=0.366)$ have statistically significantly higher scores than teachers holding either bachelor $(\mathrm{M}=4.25, \mathrm{SD}=0.432)$ or post-graduate certifications $(\mathrm{M}=4.21, \mathrm{SD}=0.456)$. There was only no statistically significant difference between junior and senior high school teachers for the school-level groups. The rest of the other groups have statistically significant differences in the mean score. While primary teachers feel the safest in SFC partnerships, the continuing school teachers feel the least safe. 
Table 3. Teachers' feelings of safeness in SFC partnerships based on background characteristics

\begin{tabular}{|c|c|c|c|c|c|}
\hline \multirow{2}{*}{ Variable } & \multicolumn{5}{|c|}{ Teachers' feelings of safeness in SFC partnerships } \\
\hline & $\mathrm{n}$ & M & SD & $\mathrm{p}$ & $\eta 2$ \\
\hline Geographic area & & & & .087 & \\
\hline Urban & 205 & 4.31 & 0.425 & & \\
\hline Rural & 129 & 4.20 & 0.452 & & \\
\hline Highland & 37 & 4.22 & 0.428 & & \\
\hline Teaching experience & & & & .001 & .04 \\
\hline$\leq 10$ years & 116 & 4.18 & 0.437 & & \\
\hline 11-20 years & 154 & 4.24 & 0.441 & & \\
\hline$>20$ years & 101 & 4.39 & 0.403 & & \\
\hline Educational background & & & & .004 & .03 \\
\hline The degree of associate & 31 & 4.51 & 0.366 & & \\
\hline Bachelor degree & 277 & 4.25 & 0.432 & & \\
\hline Post-graduate degree & 63 & 4.21 & 0.456 & & \\
\hline School-level & & & & $* * *$ & .08 \\
\hline Primary school & 89 & 4.44 & 0.385 & & \\
\hline Junior high school & 132 & 4.24 & 0.407 & & \\
\hline Senior high school & 101 & 4.24 & 0.461 & & \\
\hline Continuing education & 49 & 4.04 & 0.436 & & \\
\hline
\end{tabular}

Table 4. Post hoc comparisons in teachers' feelings of safeness in SFC partnerships

\begin{tabular}{cccc}
\hline \multicolumn{2}{c}{ Demographic category } & \multicolumn{2}{c}{ Teachers' feelings of safeness in SFC partnerships } \\
I & $\mathrm{J}$ & -0.06 & SE \\
\hline Teaching experience & 11-20 years & $\mathbf{- 0 . 2 1}$ & 0.053 \\
$\leq 10$ years & $>20$ years & $\mathbf{- 0 . 1 5}$ & 0.058 \\
$\leq 10$ years & $>20$ years & & 0.055 \\
$11-20$ years & & $\mathbf{0 . 2 6}$ & 0.082 \\
Educational background & Bachelor degree & $\mathbf{0 . 2 9}$ & 0.095 \\
The degree of associate & Post-graduate degree & 0.04 & 0.060 \\
The degree of associate & Post-graduate degree & & 0.058 \\
Bachelor degree & & $\mathbf{0 . 2 0}$ & 0.061 \\
School-level & Junior high school & $\mathbf{0 . 2 0}$ & 0.075 \\
Primary school & Senior high school & $\mathbf{0 . 4 0}$ & 0.056 \\
Primary school & Continuing education & 0.01 & 0.071 \\
Primary school & Senior high school & $\mathbf{0 . 2 0}$ & 0.073 \\
Junior high school & Continuing education & $\mathbf{0 . 2 0}$ & \\
Junior high school & Continuing education & &
\end{tabular}

pote

$\mathrm{SE}=$ Standard Error.

\subsection{Correlations}

Table 5 illustrates the correlation coefficients between all variables. Teachers' feelings of safeness in SFC partnerships were statistically significantly correlated with almost all of the variables. Teachers' feelings of safety were positive statistically significantly linked with collaborative actions between teachers and families, families' mental encouragement for teachers, and collaborated actions between families and communities. Only two variables related to school-level, namely primary school and continuing school, statistically significantly correlated with sub-instruments. However, two such correlations are the opposite. While primary school variable positive statistically significantly linked, continuing school variable linked with all four sub-instruments. For variables related to teaching experience, only more than 20 teaching-year positively statistically significantly correlated with all four sub-instruments. The rest of the teaching-year variables has no statistically significant correlations with all four sub-instruments. Only the diploma variable had positive statistically significant correlations with all four sub-instruments for variables related to educational backgrounds. 
Table 5. Correlations coefficients

\begin{tabular}{|c|c|c|c|c|c|c|c|c|c|c|c|c|c|c|c|c|c|}
\hline & 1 & 2 & 3 & 4 & 5 & 6 & 7 & 8 & 9 & 10 & 11 & 12 & 13 & 14 & 15 & 16 & 17 \\
\hline 1. Senior high school & 1 & & & & & & & & & & & & & & & & \\
\hline 2. Junior high school & $\begin{array}{l}-.46 \\
* *\end{array}$ & 1 & & & & & & & & & & & & & & & \\
\hline 3. Primary school & $\begin{array}{l}-.34 \\
* *\end{array}$ & $\begin{array}{l}-.42 \\
* *\end{array}$ & 1 & & & & & & & & & & & & & & \\
\hline 4. Continuing school & $\begin{array}{c}-.24 \\
* *\end{array}$ & $\begin{array}{l}-.29 \\
* *\end{array}$ & $\begin{array}{l}-.22 \\
* *\end{array}$ & 1 & & & & & & & & & & & & & \\
\hline 5. $\leq 10$ years & .05 & -.03 & $\begin{array}{l}-.11 \\
*\end{array}$ & $\begin{array}{l}.12 \\
*\end{array}$ & 1 & & & & & & & & & & & & \\
\hline 6. $11-20$ years & .09 & -.03 & -.05 & -.01 & $\begin{array}{l}-.57 \\
* *\end{array}$ & 1 & & & & & & & & & & & \\
\hline 7. $>20$ years & $\begin{array}{l}-.14 \\
* *\end{array}$ & .06 & $\begin{array}{l}.17 \\
* *\end{array}$ & $\begin{array}{c}-.11 \\
*\end{array}$ & $\begin{array}{l}-.41 \\
* *\end{array}$ & $\begin{array}{l}-.52 \\
* *\end{array}$ & 1 & & & & & & & & & & \\
\hline 8. Urban area & -.05 & -.09 & .05 & $\begin{array}{l}.13 \\
*\end{array}$ & .07 & -.03 & -.03 & 1 & & & & & & & & & \\
\hline 9. Rural area & -.04 & $\begin{array}{l}.13 \\
*\end{array}$ & -.03 & -.08 & -.08 & .03 & .05 & $\begin{array}{l}-.81 \\
* *\end{array}$ & 1 & & & & & & & & \\
\hline 10. Highland area & $\begin{array}{l}.14 \\
* *\end{array}$ & -.06 & -.02 & -.08 & .01 & .01 & -.02 & $\begin{array}{l}-.37 \\
* *\end{array}$ & $\begin{array}{l}-.24 \\
* *\end{array}$ & 1 & & & & & & & \\
\hline 11. Diploma & $\begin{array}{l}-.19 \\
* *\end{array}$ & .08 & $\begin{array}{l}.17 \\
* *\end{array}$ & -.09 & -.08 & .02 & .06 & -.08 & .01 & $\begin{array}{l}.13 \\
*\end{array}$ & 1 & & & & & & \\
\hline 12. Bachelor degree & $\begin{array}{l}-.24 \\
* *\end{array}$ & $\begin{array}{l}.16 \\
* *\end{array}$ & .08 & -.01 & $\begin{array}{l}.13 \\
*\end{array}$ & $\begin{array}{l}-.13 \\
*\end{array}$ & .01 & -.08 & $\begin{array}{l}.14 \\
* *\end{array}$ & -.10 & $\begin{array}{l}-.52 \\
* *\end{array}$ & 1 & & & & & \\
\hline $\begin{array}{l}\text { 13. Post-graduate } \\
\text { degree }\end{array}$ & $\begin{array}{l}.42 \\
* *\end{array}$ & $\begin{array}{l}-.25 \\
* *\end{array}$ & $\begin{array}{l}-.22 \\
* *\end{array}$ & .08 & -.09 & $\begin{array}{l}.13 \\
*\end{array}$ & -.05 & $\begin{array}{l}.15 \\
* *\end{array}$ & $\begin{array}{l}-.16 \\
* *\end{array}$ & .02 & $\begin{array}{l}-.14 \\
* *\end{array}$ & $\begin{array}{l}-.78 \\
* *\end{array}$ & 1 & & & & \\
\hline 14. Sub-instrument 2 & -.05 & .02 & $\begin{array}{l}.15 \\
* *\end{array}$ & $\begin{array}{l}-.15 \\
* *\end{array}$ & -.07 & -.10 & $\begin{array}{l}.18 \\
* *\end{array}$ & $\begin{array}{l}.14 \\
* *\end{array}$ & $\begin{array}{c}-.11 \\
*\end{array}$ & -.05 & $\begin{array}{l}.10 \\
*\end{array}$ & -.01 & -.07 & 1 & & & \\
\hline 15. Sub-instrument 3 & .02 & -.08 & $\begin{array}{l}.15 \\
* *\end{array}$ & $\begin{array}{l}-.10 \\
*\end{array}$ & -.08 & -.06 & $\begin{array}{l}.15 \\
* *\end{array}$ & .08 & -.10 & .03 & $\begin{array}{l}.18 \\
* *\end{array}$ & -.06 & -.06 & $\begin{array}{l}.69 \\
* *\end{array}$ & 1 & & \\
\hline 16. Sub-instrument 4 & -.09 & .00 & $\begin{array}{l}.20 \\
* *\end{array}$ & $\begin{array}{l}-.14 \\
* *\end{array}$ & -.07 & -.06 & $\begin{array}{l}.14 \\
* *\end{array}$ & .02 & -.01 & -.01 & $\begin{array}{l}.18 \\
* *\end{array}$ & .12 & $\begin{array}{l}-.27 \\
* *\end{array}$ & $\begin{array}{l}.53 \\
* *\end{array}$ & $\begin{array}{l}.45 \\
* *\end{array}$ & 1 & \\
\hline $\begin{array}{l}\text { 17. Teachers' } \\
\text { feelings of safeness }\end{array}$ & -.04 & -.03 & $\begin{array}{l}.23 \\
* *\end{array}$ & $\begin{array}{l}-.20 \\
* *\end{array}$ & $\begin{array}{l}-.13 \\
*\end{array}$ & -.04 & $\begin{array}{l}.18 \\
* *\end{array}$ & $\begin{array}{l}.12 \\
*\end{array}$ & -.10 & -.04 & $\begin{array}{l}.17 \\
* *\end{array}$ & -.06 & -.05 & $\begin{array}{l}.72 \\
* *\end{array}$ & $\begin{array}{l}.66 \\
* *\end{array}$ & $\begin{array}{l}.47 \\
* *\end{array}$ & 1 \\
\hline
\end{tabular}

** Correlation is significant at the 0.01 level (2-tailed).

* Correlation is significant at the 0.05 level (2-tailed).

\subsection{Regression results}

Three direct regression analyses were conducted because effects from one group of variables could disappear if taking into account all groups of variables. Firstly, the background model had only variables related to teachers' background, mainly school level, teaching experiences, school location, and educational background. The second model (partnership model) had only variables preferring to SFC partnerships, namely collaborated actions between teachers and families, families' mental encouragement for teachers, and collaborated actions between families and communities. All kinds of variables were taken into the third model (full model).

Based on previous analysis, primary school teachers, more than 20 experience-year teachers, and teachers with diploma degrees had the statistically highest safety in SFC partnership. Therefore, the three aforementioned groups were set as reference groups in the regression model. Besides, the teachers in highland were set as the reference group because comparing to urban and rural teachers, and highland teachers were the smallest sample. Finally, there are four reference groups in regression models. Table 6 illustrates in standardized beta weights, $\mathrm{p}$ values, and amount of explained variances of predictor variables. 
Table 6. Standardized beta weights, $p$ values and explained variances of multiple regression analysis for variables predicting teachers' safeness in SFC partnerships

\begin{tabular}{|c|c|c|c|c|c|c|}
\hline & \multicolumn{2}{|c|}{ Background model } & \multicolumn{2}{|c|}{ Partnership model } & \multicolumn{2}{|c|}{ Full model } \\
\hline & Beta & $p$ value & Beta & $p$ value & Beta & $p$ value \\
\hline Junior high school & -.111 & .113 & & & -.091 & .062 \\
\hline Senior high school & $-.170 * *$ & .007 & & & $-.093 *$ & .035 \\
\hline Continuing education & $-.260 * * *$ & $<.001$ & & & $-.140 * *$ & .001 \\
\hline$\leq 10$ years & $-.176 * *$ & .005 & & & -.050 & .245 \\
\hline $11-20$ years & $-.134 *$ & .028 & & & -.009 & .839 \\
\hline Urban & .162 & .061 & & & .062 & .304 \\
\hline Rural & .015 & .863 & & & .031 & .595 \\
\hline Bachelor degree & $-.215 * *$ & .008 & & & -.068 & .231 \\
\hline Post-graduate degree & $-.214 *$ & .015 & & & -.019 & .762 \\
\hline Sub-instrument 2 & & & $.462 * * *$ & $<.001$ & $.442 * * *$ & $<.001$ \\
\hline Sub-instrument 3 & & & $.300 * * *$ & $<.001$ & $.289 * * *$ & $<.001$ \\
\hline Sub-instrument 4 & & & $.090 *$ & .029 & .075 & .075 \\
\hline $\mathrm{R}$ square & \multicolumn{2}{|c|}{$13.1 \%$} & \multicolumn{2}{|c|}{$56.9 \%$} & \multicolumn{2}{|c|}{$59.1 \%$} \\
\hline
\end{tabular}

In the background model, three variables were not statistically significantly linked with teachers' safeness in SFC partnerships, namely junior high school, continuing school, urban teachers, and rural teachers. The rest of the variables related to background characteristics had statistically significant negative relationships with teachers' feelings of safeness in SFC partnerships. The background model accounts for $13.1 \%$ of the variations in teachers' safeness in SFC partnerships. All three variables related to SFC partnerships were statistically significantly positively linked with teachers' safeness. $56.9 \%$ of the variations were accounted for in the partnership model.

When all predictor variables were taken, the full model accounts for $59.1 \%$ variance in teachers' feelings of safeness in SFC partnerships. Four variables were statistically significantly linked with teachers' safeness. Junior high school teachers and continuing school teachers are constructively negatively connected with teachers' feelings of safeness. The negative correlations indicated that junior high school teachers and continuing school teachers had lower safeness in SFC partnerships. In contrast, collaborated actions between teachers and families and families' mental encouragement for teachers were statistically significantly positively linked with teachers' safeness. In other words, collaborated actions between teachers and families and families' mental encouragement for teachers somehow leveraged teachers' feelings of safeness in SFC partnerships. According to standardized beta weights, collaborated actions between teachers and families had the strongest connection with teachers' feelings of safeness.

\subsection{Vietnamese teachers' feelings of safeness in SFC partnerships}

Overall, Vietnamese teachers feel safe in SFC partnerships. The researchers $[13,16]$ concluded the positive relationship between psychology safety and teachers' voice-The results of the current study drawn on the promising status for effective moral education. Teachers will overcome anxiety to implement innovative activities for the improvement of schools [13]. Teachers' feelings of safeness in SFC partnerships facilitate collaborations among three spheres of influence, such as confidently communicating or proposing effective solutions to enhance the quality of moral education. In addition, teachers might straightly inform parents about children's problems related to morality because parents frequently exhibit negative feelings when parents facet the unfavorable of their children [20]. Bandura [26] indicated the bi-directional connection between personal factors, behaviors, and environmental influences. Teachers' feelings of safeness in SFC partnerships play critical roles in educating moral successfully.

\subsection{The differences in teachers' feelings of safeness in SFC partnerships among teachers' background characteristics}

There were no statistically significant differences at the $p<.05$ level among geographic groups in teachers' feelings of safeness in SFC partnerships. All education policies are unified in the whole of Vietnam. The Vietnam ministry of education and training (MOET) rigorously controls all training programs for both pre-service and in-service teachers. Most of the directive documents of MOET are not regional differences. Therefore, either the advantages or disadvantages of policies and programs are unified in urban, rural, and highland areas. Confucian culture affects society. Even though Confucian tradition may have changed in expression, the foundation is settled powerful in present-day Vietnamese life [27]. Honor teachers and respecting his teaching 'ton su trong dao' (respectful monk) is one of the tenets in Confucianism. In other words, no matter where teachers live, teachers still are strongly respected. Somehow, the honor to teachers makes teachers safer in straightly discussing the coordination of schools, families, and communities. 
Overall, the more experienced in teaching, the safer in SFC partnerships. Experienced teachers are more self-efficacy [26]. When teachers have more teaching years, teachers have not only more mastery experiences but also vicarious experiences. Teachers directly experience or learn from other teachers in coordinating SFC partnerships. Consequently, it is reasonable that the more experienced teachers feel safer in SFC partnerships. Besides, from the Confucian tradition, relationships in society are always hierarchical [7]. The voices of elderly people make more sense. The least experienced teachers feel insecure about unconfident in making decisions in SFC partnerships.

Consequently, it is problematic how to facilitate least experienced teachers to be safer and more confident in SFC partnerships. Fantilli and McDougall [28] pointed out that the least experienced teachers faced challenges when communicating with students' families, stemming from sentiments of insecurity. Such difficulties are exacerbated when least experienced teachers in "communities characterized by vocal and/or demanding parent groups [28]. The needs of program, policies, mentors for least experienced teachers emerged so that least experienced teachers are supported knowledge and skills to coordinate in SFC partnerships.

The results show that primary teachers feel the safest in SFC partnerships. Comparing to junior and senior high schools, parents take more care of students. In primary schools, families have more opportunities to meet and discuss students' current status because families have to go to the schools to take children day by day. The frequent conversations lead teachers to be more confident and familiar with families to have effective SFC partnerships. Besides, primary students obey more frequently than junior and senior high school students. In junior and senior high schools, enabling students to a high education level becomes mainly rather than social relationships [29]. The interactions among SFC partnerships are less important than students' learning outcomes. Academic learning outcomes are the most important. In addition, ethical leaderships that strongly affect teachers' feeling of safeness are different in school levels [16]. The researcher [16] concluded that leaders play an important role in creating a climate of safety and ethical culture.

In contrast to primary school teachers, teachers in continuing schools feel the least safe in SFC partnerships. In the Vietnam context, most of the students in continuing schools have lower learning achievement and/ or attitude than students in senior high schools. Most of the students in continuing schools do not persuade having higher educations. In other words, students in continuing schools have less motivation in learning and enhancing attitude. Besides, in continuing schools, parents and society have less attention than other schools. Teachers in continuing schools have many barriers to coordinate in SFC partnerships. Notably, while students in continuing schools should be attended to educating moral, teachers in continuing schools feel the least safe in SFC partnerships. The question is raised on how to inspire continuing school teachers to coordinate in SFC partnerships well.

\subsection{The predictor variables of teachers' feelings of safeness in SFC partnerships}

The senior high school teachers and continuing school teachers had negative correlations with teachers' feelings of safeness in SFC partnership in both the background and full models. Variables related to school-level strongly affected teachers' feelings of safeness in SFC partnerships. In other words, to leverage teachers' feelings of safeness in SFC partnerships, moral education should be specialized for each schoollevel. Especially for continuing schools, typical moral education is essential. Notable, moral education is the broad term that is beyond the formal moral education in textbooks.

In the full model, when having variables related to SFC partnerships' actions, the effects of teaching years and educational backgrounds somehow disappeared. Interestingly, many researchers indicated that such variables strongly affect teachers' attitudes in education. That means collaborated actions between teachers and families, families' mental encouragement for teachers, and collaborated actions between families and communities mainly affect teachers' feelings of safeness in SFC partnerships. While rapid technological developments facilitate communications and information exchange, face-to-face meetings between teachers and families are valuable to leverage sympathy and collaborate effectively [30]. Since IQR of sub-instrument 4 is the biggest, and the mean of sub-instrument 4 is the lowest, teachers have a diversity of views of collaborated actions between families and communities. That calls for further research to examine whether collaborated actions between families and communities have not been effective or teachers have not had adequate views on collaborated actions between families and communities. For example, effective collaborations demand the synchronous goals and purpose among SFC partnerships [31].

\subsection{The practical implication to leverage teachers' motivations}

Collaborated actions between schools and families and families' mental encouragement highly affect teachers' feelings of safety in SFC partnerships in both the SFC partnership model and the full model. Especially, actions between schools and families have the biggest beta weight in both the SFC partnership model and the full model. To reinforce teachers' feelings of safety in SFC partnerships, practical implications 
such as conference meetings or workshops play important roles. Such practical implications are friendly spaces for effective interaction between teachers and parents. Besides, parents and teachers will be shred and understood to make a sustainable relationship in educating students. Being trusted and shared helps teachers to be motivated in the betterment of moral education. Notably, the researchers [32, 33] assessed parental involvement in students' performance. Parental involvement positively affects both teachers and students. However, parental involvement in education still has obstacles or difficulties such as lack of time, lack of confidence in the educational system, or hostile attitude [34].

Broadly, school culture should be built to strong shared ethical implications that can sustain teachers' moral education involvement [35]. Nowadays, students come from diverse families who differ from social economics and cultural or academic background [36]. Meanwhile, teachers felt unprepared to collaborate with students' families effectively [37]. While family engagements and supports are essential to help students achieve academic knowledge and social skills successfully, educators, administrators need to know how to interact effectively with teachers and families to contribute to the ecosystems of moral education. Based on effective partnerships, teachers will get more motivation.

\section{CONCLUSION}

While moral education is not located in the moral subject per se, SFC partnerships' operation plays a critical role. To have great coordination, teachers, administrators, and parents need to know how to communicate in positive ways that build mutual respect, trust, and appreciation of each other. Again, teachers' feelings of safeness in SFC partnerships are the prerequisite to have sustainable collaborations.

The simple random sampling could be one of the weaknesses in this study when the sample was taken in many Vietnam regions. However, this current study has important results in exploring and enhancing teachers' feeling of safeness in SFC partnerships. To have effective moral education, together with changes in moral curriculum and textbooks, changes in teachers' preparations and development are essentially created. The teacher evaluated that the institution's coverage was inadequate and that teachers' graduates were unprepared to work effectively with students' families in the schools they are placed in. The education universities need to have training courses to supply academic knowledge and skills to collaborate with families, schools, and communities. Besides, collaborative actions between teachers and families and families' mental encouragement for teachers should reinforce teachers' safety feelings in SFC partnerships.

\section{ACKNOWLEDGEMENTS}

This work was supported by the Ministry of Education and Training (MOET), Vietnam, under the grant number KHGD/16-20.DT.024, "Model of Family-School-Society partnership on moral, lifestyle education for fulfilled of requirement of nation innovation and international integration" of Hanoi national university of education (HNUE).

\section{REFERENCES}

[1] J. C. van der Kooij, D. J. de Ruyter, and S. Miedema, "The influence of moral education on the personal worldview of students," Journal of Moral Education, vol. 44, no. 3, pp. 346-363, 2015.

[2] S. Frisancho and G. E. Delgado, "Moral education as intercultural moral education," Intercultural Education, vol. 29, no. 1, pp. 18-39, 2018.

[3] J. R. Rest, M. J. Bebeau, and D. Navarez, "Beyond the Promise: A Perspective on Research in Moral Education," Educational Researcher, vol. 28, no. 4, pp. 18-26, 1999.

[4] J. Schuitema, G. Ten Dam, and W. Veugelers, "Teaching strategies for moral education: A review," Journal of Curriculum Studies, vol. 40, no. 1, pp. 69-89, 2008.

[5] C. Vengadasalam, W. Hasmah, W. Mamat, and F. Mail, "Domain Approach: An Alternative Approach in Moral Education," Malaysian Online Journal of Educational Sciences, vol. 2, no. 4, pp. 1-12, 2014.

[6] D. H. Doan, "Moral education or political education in the Vietnamese educational system?" Journal of Moral Education, vol. 34, no. 4, pp. 451-463, 2005.

[7] R. Burr, "The complexity of morality: Being a 'good child' in Vietnam?" Journal of Moral Education, vol. 43, no. 2, pp. 156-168, 2014.

[8] L. Fang, R. C. F. Sun, and M. Yuen, "'Be useful to society': parental academic involvement in rural to urban migrant children's education in China," Asia Pacific Education Review, vol. 18, no. 3, pp. 361-371, 2017.

[9] J. Kim and J. Bryan, "A First Step to a Conceptual Framework of Parent Empowerment: Exploring Relationships Between Parent Empowerment and Academic Performance in a National Sample," Journal of Counseling and Development, vol. 95, no. 2, pp. 168-179, 2017.

[10] J. Ziomek-Daigle, "Schools, Families, and Communities Affecting the Dropout Rate: Implications and Strategies for Family Counselors," The Family Journal, vol. 18, no. 4, pp. 377-385, 2010. 
[11] F. L. Epstein, J. L. Sanders, M. G. Simon, B. S. Salinas, K. C. Jansorn, and N. R. Van Voorhis, School, family, and community partnerships: Your handbook for action, 2nd ed. Thousand Oaks, CA: Corwin Press, 2002.

[12] R. Pring, "Education as a moral practice," Journal of Moral Education, vol. 30, no. 2, pp. 101-112, 2001.

[13] S. Bas and E. Tabancali, "Correlations between teachers' personality, psychological safety perception and teacher voice," Eurasian Journal of Educational Research, vol. 2020, no. 85, pp. 185-204, 2020.

[14] A. Edmondson, "Psychological safety and learning behavior in work teams," Administrative Science Quarterly, vol. 44, no. 2, pp. 350-383, 1999.

[15] T. I. Kulikova and D. V. Maliy, "Professional and personal qualities of the teacher in the context of the psychological safety of educational environment," European Journal of Contemporary Education, vol. 6, no. 4, pp. 715-722, 2017.

[16] M. Sağnak, "Ethical leadership and teachers' voice behavior: The mediating roles of ethical culture and psychological safety," Edicational Sciences : Theory \& Practice, vol. 17, pp. 1101-1117, 2017.

[17] R. Kark and A. Carmeli, "Predicting Marital Happiness and Stability from Newlywed Interactions Published by: National Council on Family Relations Predicting Marital Happiness and Stability from Newlywed Interactions," Journal of Marriage and Family, vol. 30, pp. 785-804, 2009.

[18] K. Swick, "Communication Concepts for Strengthening Family-School-Community Partnerships," Early Childhood Education Journal, vol. 30, no. 4, pp. 275-280, 2003.

[19] G. Hornby and R. Lafaele, "Barriers to parental involvement in education: An explanatory model," Educational Review, vol. 63, no. 1, pp. 37-52, 2011.

[20] R. M. Gargiulo and S. B. Graves, "Parental Feelings: The Forgotten Component When Working with Parents of Handicapped Preschool Children," Childhood Education, vol. 67, no. 3, pp. 176-178, 1991.

[21] D. Aslan, "Primary School Teachers' Perception on Parental Involment: A Quliatative Case Study," International Journal of Higher Education, vol. 5, no. 2, pp. 131-147, 2016.

[22] A. Bandura, Social foundations of thought and action: A social cognitive theory. Englewood Cliffs, NJ: PrenticeHall, 1986.

[23] P. S. Visser, J. A. Krosnick, and P. J. Lavrakas, “Chapter 9: Survey Research,” in H. T. Reis \& C. M. Judd, Ed. Handbook of research methods in social and personality psychology. New York, NY, US: Cambridge University Press, 2000, pp. 223-252.

[24] K. Cohen, L. Manion, and L. Morrison, Research Methods in Education, 8th ed. New York: Routledge, 2018.

[25] J. W. Cohen, Statistical Power Analysis for the Behavioral Sciences, 2nd ed. Hillsdale, NJ: Lawrence Erlbaum Associates, 1988.

[26] A. Bandura, Self-efficacy: The exercise of control. New York: Freeman, 1977.

[27] P. D. Nghia, "Confucianism and the conception of the law in Vietnam," in J. Gillespie and P. Nicholson, Eds. Asian socialism and legal change: The Dynamics and Vietnamese and Chinese Reform, no. August 2005. Canberra, Australia: ANUE Press and Asian Pacific Press, 2005, pp. 76-90.

[28] R. D. Fantilli and D. E. McDougall, "A study of novice teachers: Challenges and supports in the first years," Teaching and Teacher Education, vol. 25, no. 6, pp. 814-825, 2009.

[29] Chi-Ming Lee, "Changes and challenges for moral education in Taiwan," Journal of Moral Education, vol. 33, no. 4, pp. 575-595, 2004.

[30] H. Nguyen Thi, "The combination with family-school-society in educating children's morals and good behaviors: Study of France's education," Journal of Science Educational Science, vol. 64, no. 9, pp. 25-33, 2019.

[31] L. Nguyen Thi Ngoc and B. Nguyen Van, "School-family-society model on moral, life styles education-from theory to practice," Journal of Science Educational Science, vol. 64, no. 9, pp. 34-45, 2019.

[32] T. Safaria and H. Suyono, "The role of parent-child relationship, school climate, happiness, and empathy to predict cyberbullying behavior," International Journal of Evaluation and Research in Education (IJERE), vol. 9, no. 3, pp. 548-557, 2020.

[33] M. Avnet, D. Makara, K. H. Larwin, and M. Erickson, "The impact of parental involvement and education on academic achievement in elementary school," International Journal of Evaluation and Research in Education (IJERE), vol. 8, no. 3, pp. 476-483, 2019.

[34] A. Margaritoiu and S. Eftimie, "Some issues concerning school-families partnership," Procedia-Social and Behavioral Sciences, vol. 11, pp. 42-46, 2011.

[35] M. Asif, M. Qing, J. Hwang, and H. Shi, "Ethical leadership, affective commitment,work engagement, and creativity: Testing a multiple mediation approach," Sustainability (Switzerland), vol. 11, no. 16, 2019.

[36] J. L. Epstein, "Ready or not? Preparing future educators for school, family, and community partnerships," Teaching Education, vol. 24, no. 2, pp. 115-118, 2013.

[37] J. L. Epstein and M. G. Sanders, "Prospects for change: Preparing educators for school, family, and community partnerships," Peabody Journal of Education, vol. 81, no. 2, pp. 81-120, 2006. 